\title{
Proceeding
}

Supplementary Issue: Spring Conferences of Sports Science. First International Conference in Iraq on Sport for Peace, 4 April 2019. Baghdad Science Institute, Baghdad, Iraq.

\section{Features of the modern method of training the bench press in power lifting for girls}

\author{
AYGUL BAKIROVA ${ }^{1}$, RUZEL KHABIBULLIN¹, RUSLAN BIKIMBETOV ${ }^{1}$, AYRAT KHASANOV ${ }^{1}$, ILMIR \\ KHABIBULLIN2 \\ ${ }^{1}$ Department of Physical Education, Sports and Tourism, Federal State Budgetary Educational Institution of \\ Higher Education Bashkir State Agrarian University, Ufa, Russian Federation \\ ${ }^{2}$ Department Beekeeping, Private Zootechny and Breeding of Animals, Federal State Budgetary Educational \\ Institution of Higher Education Bashkir State Agrarian University, Ufa, Russian Federation
}

\begin{abstract}
The goal of the research is the theoretical and experimental justification of the effectiveness of the developed set of exercises based on the use of resistance band exercises. For the first time at the Bashkir State Agrarian Universitya set of exercises was developed and experimentally substantiated, including specially-preparatory exercises based on the performance of the developed set of exercises. The implementation of this set of exercises aimed at the in-depth training of the bench press technique in power lifting will improve the level of technical skills and power performance of power lifters in the bench press. Keywords: Power lifting; Bench press; Set of exercises; Learning; Performance techniques; In-depth training; Technical skills; Resistance band exercises; Bar weight.
\end{abstract}

\section{Cite this article as:}

Bakirova, A., Khabibullin, R., Bikimbetov, R., Khasanov, A., \& Khabibullin, I. (2019). Features of the modern method of training the bench press in power lifting for girls. Journal of Human Sport and Exercise, 14(4proc), S535-S542. doi:https://doi.org/10.14198/ihse.2019.14.Proc4.11

\footnotetext{
Corresponding author. Department of Physical Education, Sports and Tourism, Federal State Budgetary Educational Institution of Higher Education Bashkir State Agrarian University, Ufa, Russian Federation.

E-mail: ygul.bakirova.89@bk.ru

Supplementary Issue: Spring Conferences of Sports Science. First International Conference in Iraq on Sport for Peace, 4 April 2019. Baghdad Science Institute, Baghdad, Iraq.

JOURNAL OF HUMAN SPORT \& EXERCISE ISSN 1988-5202

(c) Faculty of Education. University of Alicante

doi:10.14198/jhse.2019.14.Proc4.11
} 


\section{INTRODUCTION AND IMPORTANCE OF RESEARCH}

Muscle strength is the fundamental principle of a person's physical development and is of the utmost significance. However, in everyday life, during the preparation of students for professional activity, young people are often unable to overcome difficulties associated with manifestations of maximum power tensions, since the system of physical education of young students practically does not use intensive, technically correct strength exercises (Voisin et al., 2016). Power lifting (power triathlon) is a sport in which athletes compete in certain weight classes, trying to increase the maximum weight in three types of exercises: squat, bench press, dead lift (Shafikova \& Greb, 2018). Each competitive exercise has its own specific technique. The main feature of the performance of competitive exercises is a dynamic, overcoming mode of the muscle work at a slow uniform pace, and the movement of the bar should be carried out without acceleration, at a constant speed (Aksenov \& Andryushchenko, 2018; Samsonova et al., 2018).

The bench press is the second competitive power lifting exercise. The technique of this exercise consists of 7 phases: taking the pre-starting position, starting position (fixing the bar with straight arms), lowering the bar on the chest, fixing the pause with the bar on the chest, actual bench press, fixing the bar in the final position, returning the bar to the racks(Chesnokov \& Fenzel, 2016). In power lifting practice, a range of training exercises is designed, as a rule, to use traditional weights (bar, discs, dumbbells, kettle bells, gym machines, block devices), which can be classified as "permanent" due to the fact that in the process of doing the exercise the weight remains unchanged. However, exercises with traditional weights rather quickly lead to stabilization of motor skills, which becomes the limiting factor for the further progress of sports technique in power lifting (Ogulchansky \& Sedykh, 2017; Habibullin et al., 2018). There are no objective instrumentation data on the biomechanical structure of training and competitive exercises, scientifically based recommendations on the use of tools and methods in the training process of power lifters (Banting et al., 2015; Habibullin et al., 2018).Foreign experts recommend, along with traditional weights, using non-traditional "variables" (chains, resistance bands), with which the weight magnitude, and hence the load on the muscles, depends on the angle of flexion in the working unit joint. But these recommendations are rather based on coaching practical experience without a deep scientific justification of their impact mechanism and the effect of their use (Voisin et al., 2016; Sheiko \& Sarychev, 2017). Exercises with variable weights, that is, resistance band exercises allow you to fine adjust the dynamics of effort when lifting the bar, to emphasize the peak of effort at a certain point of movement, enhance intermuscular coordination by improving the quality of interaction of working and supporting pulls of muscles(Samsonov and Sheiko, 2016; Habibullin et al., 2018b; Yakubenko, 2016). One of the problems of training athletes in power lifting is teaching the technique of competitive exercises. As a number of authors point out, coaches have a particular difficulty in individualizing the technique of competitive exercises, while the anatomical and physiological features of power lifters are poorly taken into account (Ldokova et al., 2017). All this hinders the progress of athletes, they do not achieve a tangible result and often receive serious injuries (Nikolaev \& Nikolaeva, 2017). There is a contradiction between the need for individualization of the technique of performing competitive exercises of power lifters. Also, the problems of training in power lifting include the insufficiency of modern literature for teaching bench press techniques at the stage of in-depth learning. In connection with the above, a contradiction arises between the need to teach the bench press technique in power lifting for girls at the stage of in-depth training and the insufficiency of the developed sets of exercises. The revealed contradiction determined the research topic: the content of a set of exercises aimed at training the bench press technique at the stage of in-depth learning in power lifting for girls aged 18-19. It is assumed that the implemented set of exercises will increase the level of technical degree of fitness at the stage of in-depth training of the bench press in power lifting for girls aged 18-19. The research object: training process in power lifting for girls aged 18-19, aimed at in-depth training of the bench 
press technique. The research subject: a developed set of exercises aimed at in-depth training of the bench press technique in power lifting for girls aged 18-19.

\section{METHODS}

The research, taking into account the tasks to be solved, has three relative stages. The first stage (September 2017 - March 2018). This stage includes the analysis of the scientific and methodological literature on the research topic, development of a set of technical actions aimed at the in-depth training of the bench press in power lifting for girls aged 18-19. The second stage (March - June 2018) suggested conducting a pedagogical experiment in the group of sports perfection of the power lifting sports group at the Bashkir State Agrarian University, as well as an assessment of muscle strength in the bench press exercise among twenty girls aged 18-19 trained in accordance with the power lifting sports school programme. The experimental group had a set of physical exercises aimed at training the bench press technique. The third stage (June-September 2018) included an assessment of muscle strength in the bench press exercise and analysis of research results using mathematical and statistical data processing methods (arithmetic average; percentage, deviations from arithmetic average; Student's t-test ) (Sheiko et al., 2013; Lubova et al., 2017; Gabitov et al., 2018). The pedagogical experiment was conducted at the sports centre of the Bashkir State Agrarian University among 20 girls aged 18-19 engaged in power lifting and having a power lifting experience of no more than six months in the $52 \mathrm{~kg}$ and $57 \mathrm{~kg}$ weight classes, which were divided into two groups: control and experimental, each group consisting of 10 people. Groups were selected so that between groups there were no significant differences in technical skills and muscle strength (Kreider et al., 2009 ; Nikolaev \& Nikolaeva, $2017 \mathrm{~b})$. The control group was trained according to the standard plan, the experimental group had a developed set of exercises aimed at the in-depth training of the bench press technique. The pedagogical observation was carried out prior to start of the experiment and upon its completion. The pedagogical observation was carried out in the form of peer review. Five coach-instructors were involved as experts, two of them of the highest qualification category, three of the first qualification category.

The girls were asked to perform a bar bench press at one time with a weight of $80 \%$ of their maximum performance. The performance technique is estimated on a scale from 0 to 1 , in each phase of the bench press (Table 1).

The content of the developed set of exercises aimed at in-depth training of the bench press technique For the experimental group, the developed set of exercises was used for training the bench press technique at the stage of in-depth learning. Exercises are performed with a resistance band:

1. Fix the bar at the second phase of the bench press, i.e. fix the bar with straight arms, for $10-15$ seconds.

2. Perform the fifth phase of the bench press at a slow pace, i.e. a slow bar lift, 10 seconds.

3. In a standing position, squeeze shoulder blades back together with a resistance band in hands. Arms at the chest level are straightened in the elbow joint.

4. Lower the stretched resistance band with arms straightened down, arms are raised up to 45 degrees, downward movement up to the thoracic section.

5. Bench press with a stretched resistance band under the heels.

6. Bench press with a resistance band on the legs. One end of the resistance band is fixed in the middle of the rack, the other is attached to the legs. 
In the framework of one session, training at this stage was conducted in the first half of the main part of the training, when there was not yet considerable fatigue, and on the first day of the training micro cycle. The exercises were performed with 3 sets of 15 wraps with a rest interval of 1.5-2 minutes (Samsonova et al., 2014).

Table 1. Classification of errors for the evaluation of bench press technique.

\begin{tabular}{|c|c|c|}
\hline No. & Violation & $\begin{array}{l}\text { Number of } \\
\text { points }\end{array}$ \\
\hline 1 & $\begin{array}{l}\text { Error in the first phase: taking the pre-starting position (position of the } \\
\text { athlete on the bench, bar grip, removing the bar from the racks, } \\
\text { location of the legs) }\end{array}$ & $0-1$ \\
\hline 2 & $\begin{array}{l}\text { Error in the second phase: the starting position (fixing the bar in a fixed } \\
\text { state with arms fully extended at the elbow joints) }\end{array}$ & $0-1$ \\
\hline 3 & Error in the third phase: lowering the bar to the chest & $0-1$ \\
\hline 4 & $\begin{array}{l}\text { Error in the fourth phase: fixing a pause with the bar on the chest } \\
\text { (keeping the bar in a fixed position on the chest with a certain visible } \\
\text { pause) }\end{array}$ & $0-1$ \\
\hline 5 & Error in the fifth phase: lift-off of the bar from the chest & $0-1$ \\
\hline 6 & $\begin{array}{l}\text { Error in the sixth phase: fixing the bar in the final position with straight } \\
\text { arms }\end{array}$ & $0-1$ \\
\hline 7 & Error in the seventh phase: return of the bar to the racks & $0-1$ \\
\hline
\end{tabular}

\section{RESULTS}

\section{Intergroup analysis of research results}

Initial results recorded prior to the experiment show that both groups (control and experimental) have relatively similar degree of training in the bench press technique. Figure 1 shows the control and experimental group results prior to the experiment. Intergroup analysis of the control and experimental groups was conducted in October 2018. In the first phase, which includes taking the pre-starting position (position of the athlete on the bench, bar grip, removing the bar from the racks, location of the legs), the control group had 0.50 points, and the experimental group 0.45 points. In the second phase, the starting position (fixing the bar 
in a fixed state with arms fully extended at the elbow joints), the control group had 0.45 points, and the experimental group 0.47 points. In the third phase, which consists in lowering the bar to the chest, the points were distributed as follows: the control group -0.35 points, the experimental group -0.45 points. In the fourth phase -fixing a pause with the bar on the chest (keeping the bar in a fixed position on the chest with a certain visible pause) the control group had 0.39 points, and the experimental group 0.36 points. In the fifth phase, which consists in lift-off of the bar from the chest, the points were as follows: the control group - 0.25 points, the experimental group - 0.35 points. In the sixth phase, where the athlete must fix the bar in the final position with straight arms, the control group had 0.48 points, and the experimental group 0.39 points. In the seventh phase - the return of the bar to the racks - the points were as follows: the control group - 0.49 points, the experimental group -0.40 points.

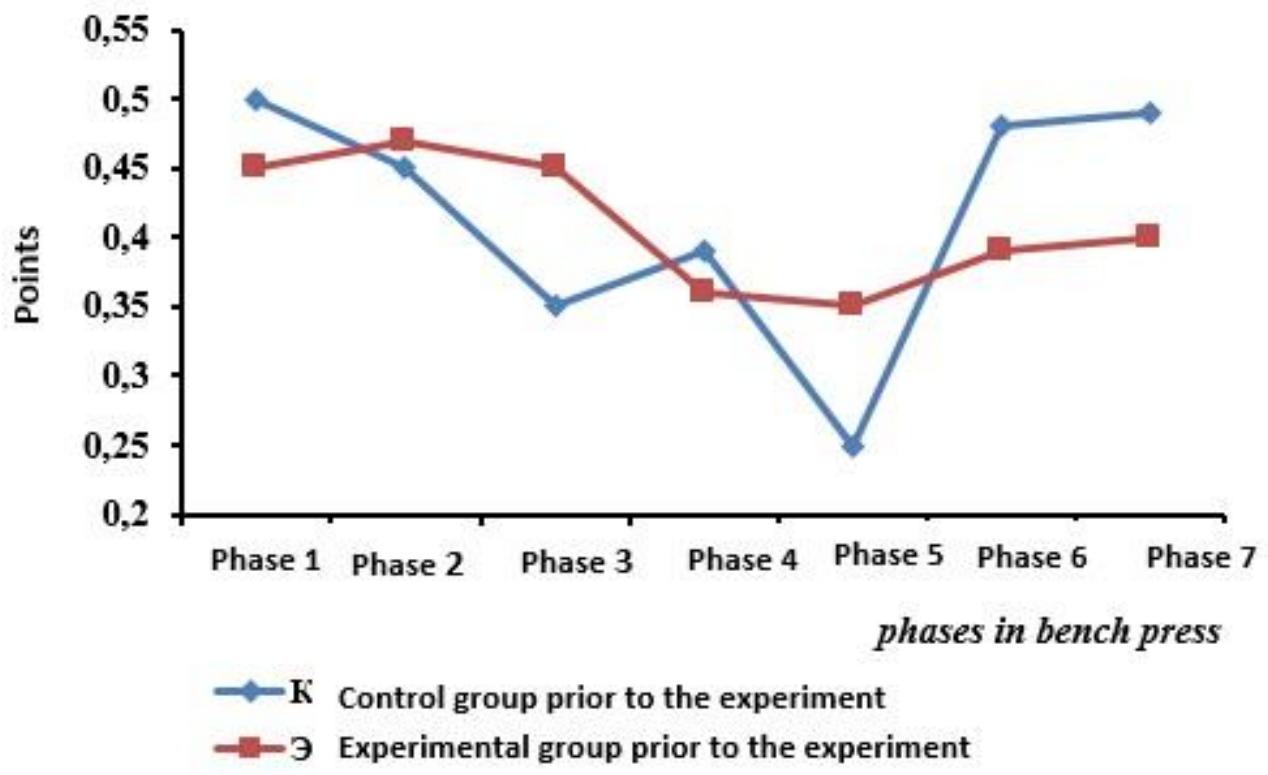

Figure1. Intergroup analysis of the control and experimental group results prior to the experiment.

Intergroup analysis of the control and experimental groups (Figure 2) upon completion of the experiment showed that in the first phase, which includes taking the pre-starting position, the control group had 0.60 points, and the experimental group 0.95 points. In the second phase, the starting position (fixing the bar in a fixed state with arms fully extended at the elbow joints), the control group had 0.50 points, and the experimental group had 0.97 points. In the third phase, which consists in lowering the bar to the chest, the points were distributed as follows: the control group - 0.45 points, the experimental group - 0.95 points. In the fourth phase - fixing a pause with the bar on the chest (keeping the bar in a fixed position on the chest with a certain visible pause) the control group had 0.49 points, and the experimental group 0.86 points. In the fifth phase, which consists in lift-off of the bar from the chest, the points were as follows: the control group - 0.35 points, the experimental group - 0.85 points. In the sixth phase, where the athlete must fix the bar in the final position with straight arms, the control group had 0.58 points, and the experimental group 0.89 points. In the seventh phase -the return of the bar to the racks - the points were as follows: the control group - 0.55 points, the experimental group -0.90 points. 


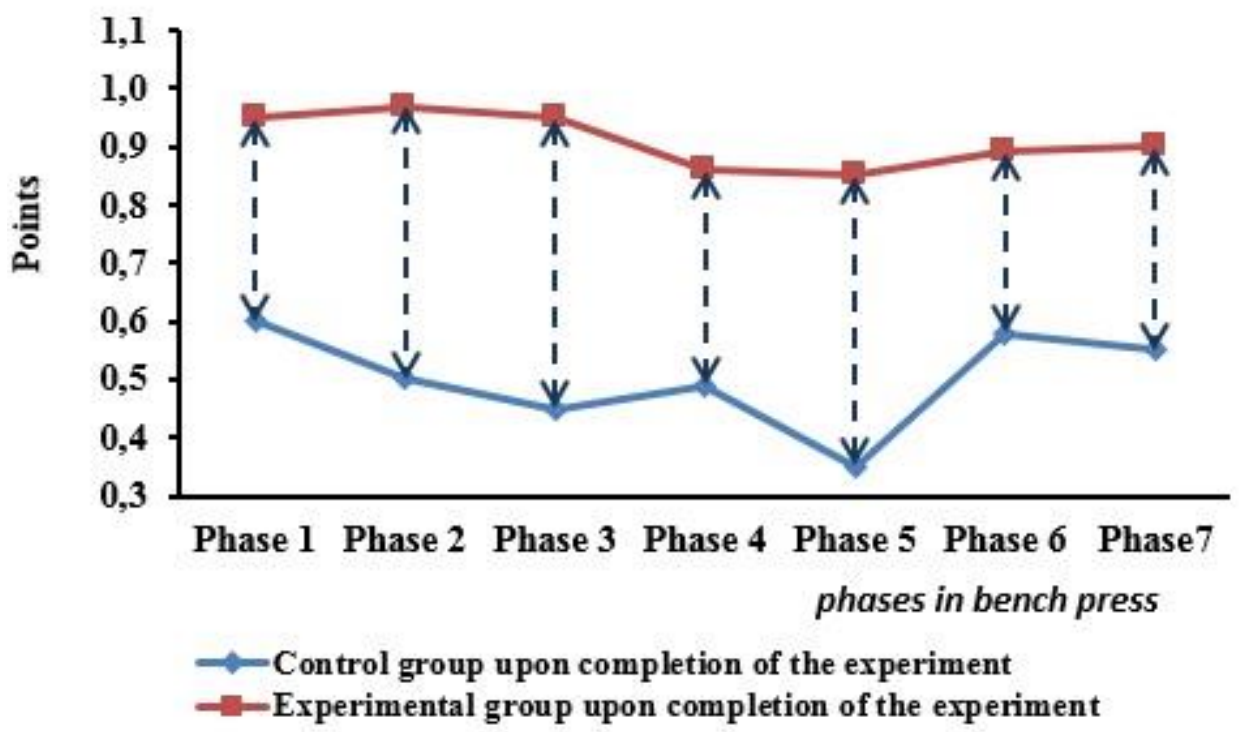

Figure2. Intergroup analysis of the control and experimental group results upon completion of the experiment.

After conducting an intergroup analysis of the results of the control and experimental groups, it can be concluded that all differences are accurately significant. The control group was inferior to the experimental one by points in all phases of the bench press, consequently, a set of exercises developed by us is effective. In the control group, muscle strength in the bench press prior to the experiment averaged $20.7 \mathrm{~kg}$, at the end of the experiment this indicator increased by only $11.4 \mathrm{~kg}$. In the experimental group, prior to the experiment, it was $20.5 \mathrm{~kg}$, and upon its completion, this indicator increased by an average of $20.4 \mathrm{~kg}$, which amounted to $40.9 \mathrm{~kg}$ (Figure 3).

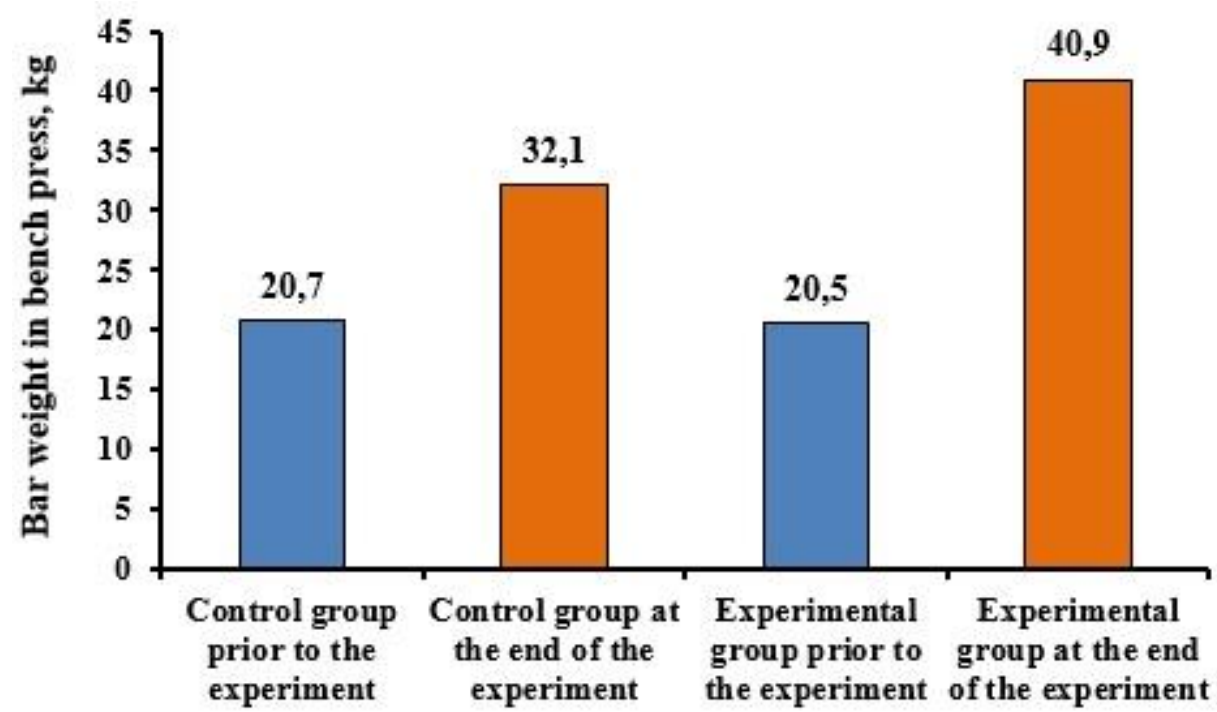

Figure3. Performance changes in the bench press in the control and experimental groups. 
Based on the experimental data, we can conclude that the developed set of exercises helps not only to increase the level of technical skill training, but also to increase muscle strength, which in turn are closely interrelated.

\section{DISCUSSION}

To determine the effectiveness of the developed set of exercises aimed at in-depth training of the bench press technique in power lifting for girls aged 18-19, we conducted an intergroup analysis of the research results which revealed accurately significant differences between the control and experimental groups in the technique and muscle strength regarding the performance of the bench press in power lifting after the experiment. The control group was inferior to the experimental one by points and by strength results in the bench press, consequently, a set of exercises developed by us is effective.

\section{CONCLUSION}

At the stage of in-depth learning of the bench press technique in power lifting for girls aged 18-19, it is recommended to apply the developed set of exercises, which includes resistance band exercises. The data obtained in the course of the research are recommended to be used in coaching and instructing, since the use of the developed set of exercises aimed at training the technique allows you to improve the level of technical skills in the in-depth training of the bench press technique in power lifting for girls aged 18-19, and also to increase the muscle strength of power lifters.

\section{REFERENCES}

Aksenov, M.O., \&Andryushchenko, L.B. (2018). Development of power skills of athletes: the role of the myostatin gene. Theory and practice of physical culture, 4, 71-74.

Banting, L. K., Pushkarev, V. P., Cieszczyk, P., Zarebska, A., Maciejewska-Karlowska, A., Sawczuk, M. A., ...\&Pushkareva, Y. E. (2015). Elite athletes' genetic predisposition for altered risk of complex metabolic traits. BMC genomics, 16(1), 25. https://doi.org/10.1186/s12864-014-1199-0

Chesnokov, A.V., \&Fenzel, A.D. (2016). Development of motor skills in technologizing training activities of the student powerlifting team. Theory and practice of physical culture,6, 61-65.

Gabitov, I.I., Badretdinov, I.D., Mudarisov, S.G., \&Khasanov,E. (2018). Modeling the Process of Heap Separation in the Grain Harvester Cleaning System. Journal of Engineering and Applied Sciences, 13, 6517-6526.

Habibullin, R.M., Ismagilova, E. R., \&Habibullin, I. M. (2018). Morphological changes of the spleen of mice during exercise and the use of adaptogens. Morphology,153(3), 289.

Habibullin, R.M., Ismagilova, E.R., \&Bakirova, A.U. (2018b). Morphology of skeletal muscle tissue in mice during exercise and the use of adaptogens. Morphology.153(3), 288-289.

Kreider, R., Leutholtz, B., Katch, F., Katch,V. (2009). Exercise and Sport Nutrition. Santa Barbara: Fitness Technologies Press, 5, 53-61.

Ldokova, G.M., Volkova, K.R., Pyanzin, A.I. (2017). Coach's actions in the system of relations coachathlete in powerlifting. Theory and practice of physical culture, 8, 72-74.

Lubova T.N., Islamgulov D.R., Ismagilov K.R., Ismagilov, R.R., Mukhametshin, A.M., Alimgafarov, R.R., Enikiev, R.I., Bakirova, A.U., Kamilanov, A.A.., \&Lebedeva,O.Yu. (2017). Economic Efficiency of Sugar Beet Production. Journal of Engineering and Applied Sciences,13(8), 6565-6569. 
Nikolaev, P.P., \&Nikolaeva, I.V. (2017). Monitoring and modern technologies in the process of organization of classes in power triathlon at the University. Theory and practice of physical culture, 11,89 .

Nikolaev, P.P., \&Nikolaeva, I.V. (2017b). Integral analysis of model morphofunctional characteristics of girls - representatives of mass athletic title in power triathlon. Theory and practice of physical culture,9, 104.

Ogulchansky, V.A., \&Sedykh, N.V. (2017). Organizing the training process in powerlifting. Theory and practice of physical culture, 7,80 .

Samsonov, G.A., \&Sheiko, B.I. (2016). Individualizing the content of technical and special power training of powerlifters in order to overcome dead zones in the bench press. Scientific notes of the University named after P.F. Lesgaft, 3(133), 210-213.

Samsonova, A.V., Sheiko, B.I., Kichigina, N.B., \&Samsonov, G.A. (2014). Electrical activity in muscles of the lower extremities when performing bench press. Scientific notes of the University named after P. F. Lesgaft, 5 (111), 159-165.

Samsonova, A.V., Ponomarev, G.N., Tsipin, L.L., \&Bogdanov, O. A. (2018). Biomechanical concept to use power exercises in athlet training. Theory and practice of physical culture,8, 65-66.

Shafikova, L.R., \&Greb, A.V. (2018). Development of strength skills in students engaged in weightlifting. Theory and practice of physical culture,6, 45-46.

Sheiko, B.I., Gorulev, P.S., Rumyantseva, E.R., \&Tsedov, R.A. (2013). Powerlifting. From a beginner to a master. Moscow, pp. 560.

Sheiko, B.I., \&Sarychev, K.I. (2017). Bench press for athletes of all levels of training and physical abilities. Moscow, pp. 523.

Yakubenko,Ja. E. (2016). Distribution of training load between separate groups of exercises in powerlifting. Theory and practice of physical culture,6, 76-78.

Voisin, S., Guilherme, J. P. F., Yan, X., Pushkarev, V. P., Cieszczyk, P., Massidda, M., ...\&Maciejewska, A. (2016). ACVR1B rs2854464 is associated with sprint/power athletic status in a large cohort of Europeans but not Brazilians. PloS one, 11(6), e0156316. https://doi.org/10.1371/journal.pone.0156316

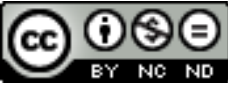

This work is licensed under a Attribution-NonCommercial-NoDerivatives 4.0 International (CC BY-NC-ND 4.0). 